\title{
Disappearance of carotene from the alimentary tract of vitamin A-deficient rats
}

\author{
By V. H. BOOTH \\ (Member of the scientific staff of the Agricultural Research Council) \\ Dunn Nutritional Laboratory, University of Cambridge and Medical Research Council \\ (Received 24 February 1956) \\ It is well known that ingested carotene is incompletely absorbed during its passage \\ through the alimentary tract. The amount absorbed is usually taken as the difference \\ between that ingested and that found in the faeces, as is done in digestion experiments. \\ This difference value includes any carotene that is destroyed in the gut: the word \\ 'disappearance' is therefore preferred to 'absorption'. \\ During the course of such absorption studies it was found that the disappearance of \\ carotene from the gut of the rat depleted of vitamin A was greater than from that of the \\ rat previously supplied with the vitamin. In this paper the disappearance is shown to \\ be related to the amount of food consumed, and a suggestion is made to explain the \\ effect.
}

\section{Animals}

\section{EXPERIMENTAL AND RESULTS}

Inbred piebald rats, born of mothers given a diet low in vitamin $A$, were weaned at 21 days old on to a vitamin A-free diet of the following percentage composition by weight: extracted casein (low-vitamin grade) I $8{ }_{5}$, sucrose 54 , arachis oil $\mathrm{I}_{4}$, dried yeast 9 , and salt mixture 4.5 . Each rat also received $2 \mathrm{mg}$ racemic $\alpha$-tocopheryl acetate and I 20 i.u. vitamin $D_{3}$ weekly. At about 5 weeks old the rats were caged individually. Xerophthalmia usually appeared at from 7 to 9 weeks of age, shortly before other signs of vitamin A deficiency were observed, such as failure to gain weight. In the present investigation either the rats in a test were all of one sex or, when both sexes were used, any difference due to sex was extracted by analysis of variance.

For tests in which some other abnormality than deficiency of vitamin A was studied the rats used had been given vitamin A. Sometimes after one test, the rats, all of them being now replete with vitamin $A$, were rested on the standard diet for a few days and used for another test.

\section{Dosage and sampling}

The amount of carotene that disappeared during its passage through the alimentary tract was determined as follows. The supplement, usually about $\mathrm{I} \cdot 8 \mathrm{~g}$ of canned carrot puree per rat, was weighed on to a small dish, lightly covered with basal diet, and offered at Io a.m. Food had previously been withheld for an hour, and the supplement was soon eaten. At 5 p.m. a sheet of absorbent paper was placed under each cage, and droppings 
were collected until 9 a.m., 3 days later. Thus the collection lasted from about the 7 th to the 7 Ist hour after dosing. The droppings were gathered separately from each rat, and softened by soaking with a few drops of hot water to facilitate the extraction of carotene. The difference between the carotene ingested and that recovered was expressed as a percentage of the former. Each rat was treated individually throughout.

\section{Determination of carotenes and lycopene}

Carotene in puree, leaves, and faeces was determined by extracting them with a cold mixture of light petroleum, acetone and quinol. The solution was washed automatically and chromatographed on alumina- $\mathrm{Na}_{2} \mathrm{SO}_{4}$ mixture, and the carotene was determined spectrophotometrically (Booth, 1956). The values reported are for total carotene (chiefly $\beta$, with some $\alpha$ ).

Lycopene was similarly extracted, from tomato puree or faeces, and adsorbed on alumina. The accompanying carotene was removed with $2 \%$ acetone in petrol. The lycopene was eluted with a $\mathrm{I}: \mathrm{I}$ mixture of acetone and light petroleum and determined on a photoelectric spectrophotometer by its extinction at $440 \mathrm{~m} \mu$. The $E_{1 \mathrm{~cm}}^{1 \%}$ was taken as 3470 (Goodwin, 1955).

\section{General procedure}

A typical experiment was performed as follows. At the first signs of deficiency thirty-two individually caged rats were divided into two similar groups. One group was given a single conditioning dose of halibut-liver oil, providing about 400 i.u. vitamin $\mathrm{A} /$ rat. For convenience, rats so treated will be described as 'non-deficient', although the fact that they had been depleted and wholly or partially repleted is recognized. The other group was undosed. Four days later every rat was given $2 \mathrm{~g}$ carrot puree, which provided I $4 \mu \mathrm{g}$ carotene. The percentage that disappeared during passage through the alimentary tract was determined by the method described. The amount that disappeared averaged $5^{6 \cdot 1}\left( \pm 0.92^{*}\right) \%$ of that ingested in the deficient rats, but only $48.7( \pm 2.08) \%$ in the rats previously given vitamin $A$, and the difference was highly significant $(P=0.0 \mathrm{x})$.

Tests of this type were repeated several times on other rats. The results are shown in Table I. In some of the tests vitamin A acetate or carotene was given as conditioning dose, and the waiting period between the conditioning dose and the test dose was varied. One test was done by giving as test dose $\mathrm{I} \cdot 9 \mathrm{~g}$ concentrated tomato juice to each rat and determining the disappearance of lycopene from the gut (Table I, last experiment). The percentage disappearance was less than that of carotene, but was similarly affected by nutritional status.

Although the percentage disappearance of carotene differed from test to test the mean difference between the percentage disappearances in depleted and repleted rats was about 7 , with a range of $3 \cdot 4-16 \cdot 1$; or expressed in another way, the disappearance from deficient rats was about $I \cdot 15$ times that in non-deficient. In two of the

\footnotetext{
* Here and throughout, \pm denotes standard error of the mean.
} 
Vol. 10

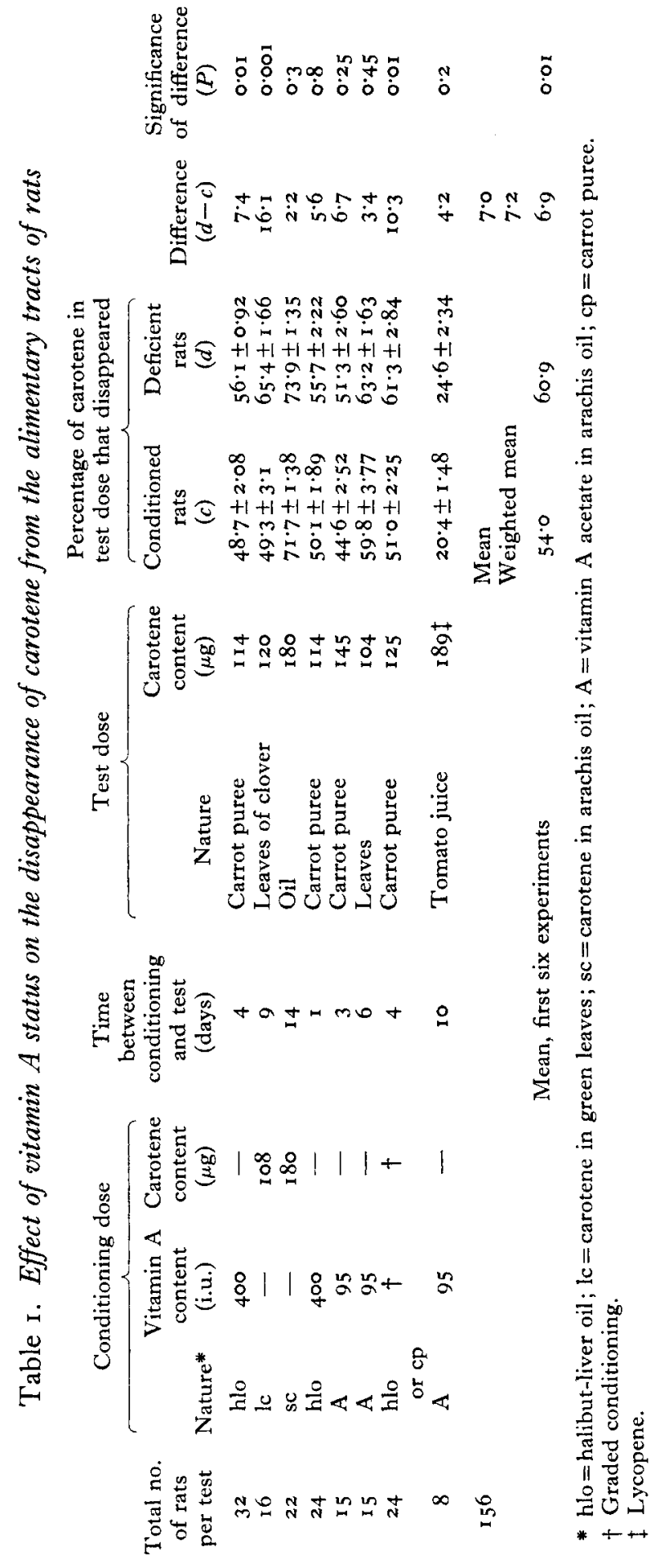


experiments the differences were statistically significant. In other individual experiments the differences though all positive were not significant, but the mean of the eight differences was significantly different from $\circ(P=0.0 \mathrm{I})$ : that is, when all the experiments were pooled, the difference was highly significant. An alternative method of computing the significance of the difference for the first six pooled experiments, that described by Fisher (1950), led to a similar conclusion. This conclusion receives support from the last two experiments.

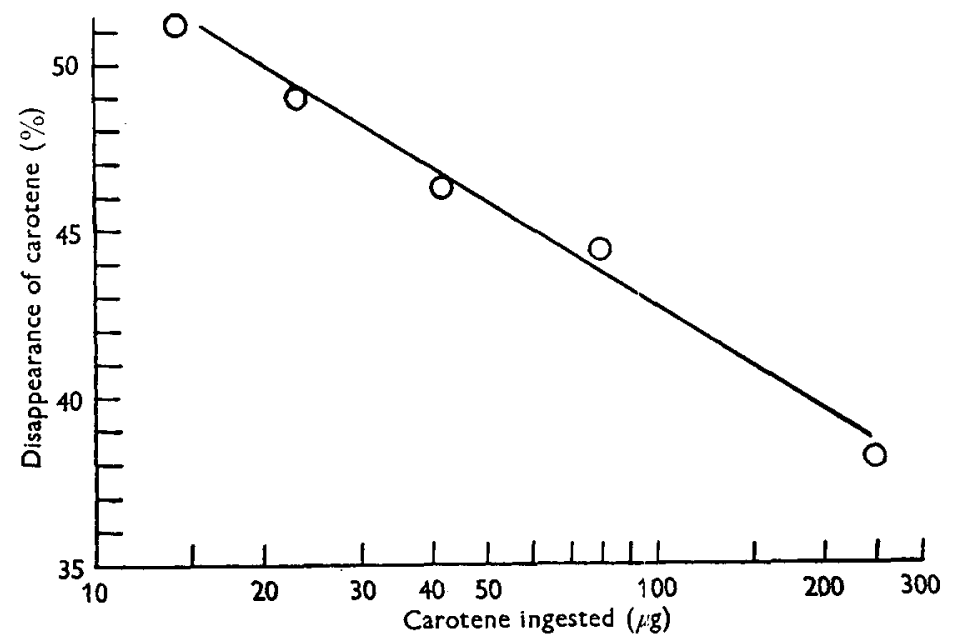

Fig. I. Percentage disappearance of carotene from the alimentary tracts of non-deficient rats given graded doses of carotene.

\section{Effect of size of test dose}

A batch of non-deficient rats was given graded test doses of carrot. The percentage disappearance of carotene was greater, the smaller the dose. The experiment was repeated six times with different preparations of carrot-raw, cooked, juice, and dehydrated-always in graded amounts. The results of the seven experiments were pooled and averaged in groups; they are shown diagrammatically in Fig. I. The correlation coefficient between the logarithm of the dose and the percentage disappearance was -0.99 within this experiment. As may be seen frora Table I, the percentage disappearance in other experiments varied from test to test. The values in Fig. I are lower than in most experiments.

\section{Effect of degree of vitamin A deficiency}

A batch of nearly depleted* rats was divided into three groups. The nine rats in one group were given graded conditioning doses of halibut-liver oil increasing logarithmically from 5 to 450 i.u. vitamin $\mathrm{A} /$ rat. The nine rats in another group were given graded conditioning doses of carrot puree, increasing logarithmically from 7 to $\mathrm{I} 60 \mu \mathrm{g}$ carotene. The five rats in the third group were given no conditioning dose. Four days later every rat was given $\mathrm{I} \cdot 8 \mathrm{~g}$ carrot puree containing $125 \mu \mathrm{g}$ carotene, and the

\footnotetext{
* The mean growth curve had become nearly flat.
} 
extent to which that carotene disappeared was estimated. The conditioning doses of puree and of halibut-liver oil were approximately equivalent in their effects, and the greater the conditioning dose of either the lower the disappearance of test doses of carotene.

\section{Effect of amount of food consumed}

Vitamin A-deficient rats consume less food and void less faeces than non-deficient rats. Non-deficient female rats 8 weeks old ate daily about $12 \mathrm{~g}$, deficient about $6 \mathrm{~g}$, of the basal diet, and voided, respectively, about 2 and $\mathrm{I} g$ of faeces in $64 \mathrm{~h}$. In three tests, batches of rats were divided each into two groups: in one group the rats were allowed to consume the basal diet ad lib., whereas the diet of the rats in the other group was restricted to that consumed by deficient rats. On the 2nd day each rat was given a dose of carotene in carrot puree, and the extent of disappearance from the alimentary tract was determined. The weights of faeces from the restricted rats resembled those from vitamin A-deficient rats. More carotene disappeared in restricted than in fully fed rats (Table 2 ), and the difference resembled the difference between vitamin-deficient and non-deficient rats.

Table 2. Effect of limiting the total food intake on the disappearance of carotene from the alimentary tract of non-deficient rats

\begin{tabular}{cccccc}
\multicolumn{5}{c}{$\begin{array}{c}\text { Percentage of carotene in } \\
\text { test dose that disappeared }\end{array}$} \\
\cline { 3 - 5 } $\begin{array}{c}\text { No. of } \\
\text { rats per } \\
\text { group }\end{array}$ & $\begin{array}{c}\text { Carotene } \\
\text { ingested }\end{array}$ & $\begin{array}{c}\text { Food } \\
\text { ad lib. }\end{array}$ & $\begin{array}{c}\text { Food } \\
\text { restricted } \\
(\mu)\end{array}$ & $\begin{array}{c}\text { Difference } \\
(r-a)\end{array}$ & $\begin{array}{c}\text { Significance } \\
\text { of difference }\end{array}$ \\
7 & 120 & $47.2 \pm 0.65$ & $55.9 \pm 3.00$ & 8.7 & 0.05 \\
15 & 145 & $44.7 \pm 2.52$ & $52.2 \pm 3.56$ & 7.5 & 0.15 \\
24 & 170 & $32.6 \pm 2.55$ & $44.8 \pm 1.15$ & 12.2 & 0.001 \\
& \multicolumn{7}{c}{ Mean } & 9.5 & $0.03^{*}$
\end{tabular}

* The probability of significance of the mean difference was calculated by the method of Fisher (1950).

\section{Effect of dietary constituents}

Yeast. In a series of tests on the disappearance of carotene the proportions of the major constituents of the diet were varied. Non-deficient rats were used for the tests. For example, a batch of fourteen rats was divided into two groups of seven: in one group the dried yeast in the diet was reduced to half its usual proportion, hence its consumption by these otherwise normally fed rats was reduced to that consumed by deficient rats. There was no effect on the disappearance of carotene $(P=0.9)$, the percentages being $49^{\cdot} 8 \pm 0 \cdot 9$ and $49^{\cdot} \cdot \pm \pm 2 \cdot 3$ in rats given less yeast and the full amount, respectively.

Fat. In several other similar tests, pairs of diets were used containing a smaller than usual, and a larger than usual, proportion of arachis oil. The percentages by weight of oil in the diet were usually 5 and 17 , the normal percentage being $\mathrm{I}_{4}$. Thus the amount of fat consumed by non-deficient rats on the low-fat diet was less than that consumed by deficient rats. Since fat is the most probable of the diet's major constituents to 
affect absorption of carotene, tests in which the proportion of it was varied were repeated several times. The results are shown in Table 3 . The effect of fat was variable and usually small. In all but one test, the amount of carotene disappearing was a little greater with the low-fat diet. The simple mean difference of 2.73 (percentage of carotene disappearing with the low-fat diet minus percentage disappearing with the high-fat diet) did not differ significantly from o $(P=0.25)$. The mean of the differences weighted by the number of rats per test was only $1 \cdot 29$ in percentage units.

\begin{tabular}{|c|c|c|c|c|c|}
\hline \multirow[b]{2}{*}{$\begin{array}{l}\text { No. of } \\
\text { rats per } \\
\text { group }\end{array}$} & \multirow[b]{2}{*}{$\begin{array}{l}\text { Carotene } \\
\text { ingested } \\
\quad(\mu \mathrm{g})\end{array}$} & \multicolumn{2}{|c|}{$\begin{array}{l}\text { Percentage of carotene in } \\
\text { test dose that disappeared }\end{array}$} & \multirow[b]{2}{*}{$\begin{array}{l}\text { Difference } \\
\quad(l-h)\end{array}$} & \multirow[b]{2}{*}{$\begin{array}{l}\text { Significance } \\
\text { of difference } \\
\qquad(P)\end{array}$} \\
\hline & & $\begin{array}{l}\text { High-fat } \\
\text { diet } \\
\quad(h)\end{array}$ & $\begin{array}{l}\text { Low-fat } \\
\text { diet } \\
\quad(l)\end{array}$ & & \\
\hline 15 & $104 *$ & $59 \cdot 8 \pm 3.77$ & $67 \cdot 9 \pm 2 \cdot 45$ & $8 \cdot I$ & 0.1 \\
\hline 16 & I $55 \dagger$ & $43 \cdot 4 \pm 2 \cdot 64$ & $44.7 \pm 3.53$ & $\mathrm{I} \cdot 3$ & 0.75 \\
\hline 24 & I $40 \dagger$ & $39 \cdot 1 \pm 2 \cdot 22$ & $32 \cdot 5 \pm 2 \cdot 17$ & $-6 \cdot 6$ & 0.05 \\
\hline I 5 & $160 \dagger$ & $33 \cdot 0 \pm 2 \cdot 39$ & $35^{\cdot 6 \pm 2 \cdot 23}$ & $2 \cdot 6$ & 0.45 \\
\hline 8 & I67t & $25 \cdot 1 \pm 3 \cdot 19$ & $33^{\cdot 2} \pm 1 \cdot 93$ & $8 \cdot \mathbf{I}$ & 0.15 \\
\hline 8 & rgot & $I 4 \cdot 5 \pm I \cdot 26$ & $17 \cdot 4 \pm 2 \cdot 06$ & $2 \cdot 9$ & 0.4 \\
\hline \multirow[t]{3}{*}{86} & & \multicolumn{2}{|c|}{ Simple mean } & +2.73 & 0.25 \\
\hline & & \multicolumn{2}{|c|}{ Weighted mean } & $+1 \cdot 29$ & \\
\hline & & \multicolumn{3}{|c|}{$\begin{array}{l}\text { * Carotene in leaves of clover. } \\
+ \text { Carotene in carrot puree. } \\
\ddagger \text { Lycopene in tomato puree. }\end{array}$} & \\
\hline
\end{tabular}

Protein. The proportion of casein in the basal diet was changed in other tests. For instance twenty-four rats were divided into two groups of twelve and given diets containing 10 and $22 \%$ casein. The percentage disappearance of carotene was $27 \cdot 4 \pm 2 \cdot 19$ and $25 \cdot 2 \pm \mathrm{I} \cdot 57$, respectively. The difference of $2 \cdot 2$ was not significant $(P=0 \cdot 45)$. In a similar test with lycopene the percentage amounts disappearing were $I 8 \cdot I \pm 2 \cdot 97$ and $17 \cdot 5 \pm 1 \cdot 79$. The difference, $0 \cdot 6$, was not significant $(P=0 \cdot 8)$.

\section{The effect of indigestible 'bulk'}

A batch of fourteen non-deficient rats was divided into two groups. One group was given the basal diet into which $5 \%$ of dry cellulose in the form of purified paper pulp had been mixed; the other group was given the basal diet alone. On the and day each rat was given a dose of $150 \mu \mathrm{g}$ carotene in carrot puree and the disappearance of carotene from the alimentary tract was determined. Another batch of eight older rats was similarly treated. Such experiments are technically difficult to perform and perhaps for that reason the results were not altogether satisfactory. They are therefore not reported in detail, but it may be worth recording that the greater the consumption of nutrient, whether mixed with cellulose or not, the greater was the amount of undigested food and of carotene excreted. 


\section{Reliability of the technique}

Precision. Carotene determinations on carrot puree were done in triplicate. The mean value for seventeen commercial specimens was $76 \cdot 3$ p.p.m. The coefficient of variation of a single determination within triplicates was $3.43 \%$.

In the experiments with the largest numbers of animals the disappearance of carotene was studied by analysis of variance methods. The sums of squares for the residual variation or 'experimental error' in those experiments were pooled and the mean square, based on 27 I degrees of freedom, was calculated. The square root, $6 \cdot 6$, is the estimated standard deviation for disappearance for one rat in percentage units. Since the percentage disappearance of carotene in this investigation averaged about 50 , the coefficient of variation for one determination would be $13 \%$, a lower value than is usually attainable in digestion experiments.

Completeness of extraction. Rat droppings are among the most difficult materials from which to extract carotene. Alternative methods, including use of the Waring Blendor, gave no improvement on our standard method. After extracting many times, using solvent liberally, carefully controlling the moisture content, and leaving the partially extracted material soaking in acetone for about an hour, virtually all the carotene was presumed to be extracted. The thoroughly ground residues were pooled and soaked overnight in acetone. A trace of pigment could be seen, but it rarely amounted to more than a further $\mathrm{I} \%$ of that already extracted.

Adequacy of collection period. No carotene was found in droppings sooner than $8 \mathrm{~h}$ after dosing. Most of the faecal carotene was recovered within 2 days of giving a dose. For instance, each of twenty-four rats was given $114 \mu \mathrm{g}$ carotene in carrot puree at noon. Faeces were collected from 5 until $45 \mathrm{~h}$ later. The carotene extracted per rat averaged $49 \mu \mathrm{g}$. A further collection for another $24 \mathrm{~h}$ yielded $4.9 \mu \mathrm{g} / \mathrm{rat}$. A negligible amount of carotene was found in a third collection. The normal collection period of from 7 to $7 \mathrm{r} \mathrm{h}$ after dosing was therefore deemed adequate.

The 'blank'. Earlier workers have found a 'carotene-like' pigment in the faeces of animals given a carotene-free diet. They deducted the 'blank' pigment from the faecal carotene obtained in a test before computing the percentage disappearance. The nature of this 'blank' was therefore investigated. When twenty rats had been maintained on the vitamin A-free diet for 3 weeks since weaning their faeces were collected for a day and extracted. A trace of yellow pigment was seen, but it was retained on the alumina during the normal assay procedure. Therefore no allowance was made for 'blank' pigment in the experiments recorded here. In other published experiments less rigorous methods than ours have been used for excluding non-carotene pigments. Much of the work on 'absorption' was published before the chromatographic technique was in general use; less specific absorbents than alumina have been used, even in some recent work; and the variable blank interfered with precision.

Destruction of carotene. The carotene that disappears during the passage of food through the alimentary tract includes any that is destroyed. The possibility of destruction by other constituents of the food was explored by the following experiments. (I) Carrot puree was mixed with basal diet and water and incubated at $23^{\circ}$ for 4 days, 
by which time moulds had grown; there was no measurable loss of carotene. (2) Three rats were given carrot puree. Next day the faeces from each were divided into two portions. One was analysed at once, the other after standing at room temperature for 12 days. The latter had $5 \%$ less carotene than the former (mean of three pairs). In another experiment faeces were similarly divided; half were kept at $13^{\circ}$ and half at $37^{\circ}$ for 6 days. The carotene content of each was the same.

These experiments offer no evidence of destruction of carotene and it seems unlikely that loss can be serious in the relatively anaerobic conditions in the rat's gut. Sexton, Mehl \& Deuel (1946) indeed observed none in the excised gastro-intestinal tract of rats kept at $37^{\circ}$ for $24 \mathrm{~h}$.

\section{DISCUSSION}

The mean percentage disappearance of carotene was about $I \cdot 15$ times as high in vitamin A-deficient as in non-deficient rats. Wagner, Günther \& Schulze (I94I) considered that there was no difference in absorption between healthy and deficient rats, but there is a hint of small differences in their tables.

In the experiments reported here, when the food intake of non-deficient rats was restricted to that voluntarily consumed by deficient rats, the percentage disappearance of carotene was much the same in both groups (Table 2). The enhanced percentage disappearance in vitamin A deficiency is therefore probably the result of lowered food intake, which in turn is due to reduced appetite. The lowered food intake might be effective through reduction either of physical bulk or of one or more of the dietary components. The proportions of protein, fat and dried yeast in the diets of vitamin A-repleted rats were reduced in turn so that each was consumed in approximately the amount consumed by deficient rats. The percentage disappearance of carotene was affected only slightly and irregularly, and it is concluded that the greater disappearance with lowered food intake cannot be linked with reduced intake of protein, fat or yeast.

The hypothesis that reduction in the physical bulk of food consumed in deficiency is the cause of increased disappearance of carotene from the alimentary tract is not easily tested experimentally. Attempts were made to increase the bulk by incorporating cellulose into the diet. The results were not helpful beyond confirming that the greater the total intake of nutrients the lower the disappearance of carotene. Fraps (1946) found that a diet made bulky with cottonseed hulls reduced the digestibility of carotene.

The chief argument for the hypothesis based on physical bulk is that the alternative hypothesis, based on chemical composition of the diet, receives no experimental support. Food passes more quickly through the alimentary tract of a normal rat with a healthy appetite than through that of a deficient rat. Carotene is never completely absorbed, and it is reasonable to believe that the faster the passage the lower the absorption. The observation that low disappearance rates were associated with high faecal weights is compatible with this view.

There are many reports in the literature (With, 1940; Sherman, I94I; Ramasarma \& Hakim, 1942) about the effect of fat on the absorption of carotene. Sometimes fat aided absorption, sometimes it had no effect. The experimental work was mostly done I 5 years or more ago when the technique of carotene determination was not accurate 
enough to establish small differences. On the other hand, it is well established that mineral oil reduces absorption. (For references see Paul, Ells \& Paul, I95 I.) It may be that digestible fat has two contrasting effects: the one to assist absorption, the other to dissolve carotene and carry it away. Indigestible mineral oil would play only the second part. The second effect would be enhanced when passage of food is rapid and much fat escapes digestion. If that be so, it may in part explain the greater excretion of carotene with high food intake.

Since vitamin A status affects the percentage disappearance of carotene from the alimentary tract, care should be taken to eliminate this complication from experiments on digestion and absorption, and when small differences are under investigation it may be advisable to control, or at least to record, the total food intake.

\section{SUMMARY}

I. Rats were depleted of vitamin A and divided into two groups. One group was given a single conditioning dose of vitamin $\mathrm{A}$ or carotene. A few days later each rat in both groups was given a dose of carotene. Faeces were collected and analysed for carotene, and the percentage of the ingested carotene that had disappeared was calculated. The term 'disappearance from the alimentary tract' is preferred to 'absorption'.

2. In many such tests (Table $\mathrm{r}$ ) an average of about $6 \mathrm{r} \%$ of the carotene in a dose disappeared in deficient rats, and only $54 \%$ in non-deficient rats. The extent to which the disappearance was less depended on the size of the conditioning dose of vitamin A, but was about the same whether the conditioning dose was halibut-liver oil or carotene.

3. Deficient rats consumed less food than non-deficient rats. When the food intake of non-deficient rats was restricted to that of deficient rats, the percentage disappearance of carotene was about the same in the two groups.

4. The amounts of the major dietary constituents consumed by non-deficient rats were in turn reduced to the amounts consumed by deficient rats. Reduction in the amount of yeast had no effect. Reduction in the amount of fat or protein slightly increased the percentage disappearance of carotene but not enough to explain the effect of the state of deficiency.

5. It is concluded that non-deficient rats, having larger appetites than those of deficient rats, ate more food which passed more quickly through the alimentary tract. Less food was digested and less carotene absorbed during the shorter period of transit.

6. Experiments were done to obtain evidence that the technique was satisfactory. The destruction of carotene was shown to be negligible in whole diet or faeces incubated for the time required to complete a test. Faeces of deficient rats contained no authentic carotene, so that no 'blank' correction was necessary. The coefficient of variation for one observation of the percentage disappearance within a group was about $13 \%$.

7. The percentage disappearance in deficient rats was inversely correlated with the amount of carotene ingested. The range of doses within each test was therefore kept small. 


\title{
REFERENCES
}

Booth, V. H. (1956). Carotene, its Determination in Biological Materials. Cambridge: W. Heffer and Sons Ltd. (In the Press.)

Fisher, R. A. (1950). Statistical Methods for Research Workers, I Ith ed. Section 21.1. London: Oliver and Boyd.

Fraps, G. S. (1946). Arch. Biochem. ro, 485 .

Goodwin, T. W. (1955). In Modern Methods of Plant Analysis. Vol. 3, p. 272. [K. Paech and M. V. Tracey, editors.] Berlin: Springer.

Paul, M. F., Ells, V. R. \& Paul, H. E. (1951). Amer. Y. dig. Dis. 18, 278.

Ramasarma, G. B. \& Hakim, D. N. (1942). Ann. Biochem. 2, I 81 .

Sexton, E. L., Mehl, J. W. \& Deuel, H. J. Jr. (1946). F. Nutr. 3r, 299.

Sherman, W. C. (194I). F. Nutr. 22, I 53 .

Wagner, K. H., Günther, L. \& Schulze, L. (194I). Vitam. u. Horm. 1, 455.

With, T. K. (1940). Absorption, Metabolism and Storage of Vitamin $A$ and Carotene. Copenhagen: Munksgaard.

\section{The effect of calcium depletion on the chemical composition of bone minerals in laying hens}

\author{
By T. G. TAYLOR AND J. H. MOORE \\ Department of Agricultural Chemistry, University of Reading
}

(Received 12. March 1956)

In a previous experiment (Taylor \& Moore, 1954) progressive mineral depletion was induced in pullets by allowing them to lay two, four or six eggs while on a calciumdeficient diet, and the degree of depletion suffered by individual bones was assessed by comparing their total ash content with that of corresponding bones from control birds which did not receive the deficient diet. Great variations were found in the extent to which the different bones had been affected. Whereas, for example, the skull, metatarsi and toes lost only small quantities of minerals, the ribs, sternum, ilia, ischia and pubis suffered severely.

In this paper the detailed chemical composition of selected bone materials from these pullets is reported, and the results are discussed in relation to current theories on the chemical nature of bone salts and on the mechanism by which minerals are lost from the skeleton.

The bones which, in the depleted birds, experienced severe loss of minerals are termed 'labile' and those which suffered only slightly 'non-labile', and one example of each type of bone and two samples of medullary bone were analysed from each pullet.

\section{EXPERIMENTAL}

Birds and their treatment. Eight Light Sussex pullets, judged as being due to lay in about a month, were placed in separate metabolism cages and fed a laying ration containing $2 \cdot 04 \% \mathrm{Ca}$. After they had laid three eggs on this ration, six of the birds were given a low-Ca diet $(0.054 \% \mathrm{Ca})$ by withholding the supplement of calcium carbonate from the standard ration. The other two birds, which were to act as controls, 